Erica Di Pierro - Sandro Bertolino - Adriano Martinoli Damiano Preatoni - Guido Tosi - Lucas A. Wauters

\title{
Estimating offspring production using capture-mark-recapture and genetic methods in red squirrels
}

Received: 9 June 2009/ Accepted: 21 October 2009/Published online: 16 December 2009

(C) The Ecological Society of Japan 2009

\begin{abstract}
Reproductive rate is a key demographic parameter of life history and population ecology. In traditional population-ecology studies of small mammals, this and other vital rates are inferred from capture-mark-recapture (CMR) data. However, CMR assumes that immigrants at first capture can be distinguished from unmarked locally born offspring, an assumption not always met. We verified CMR estimates of locally born red squirrel (Sciurus vulgaris) offspring as a measure of reproductive rate, with candidate offspring (CO)-candidate parent (mothers, CPs) assignment by CERVUS, using ten DNA microsatellite loci. Seventytwo of 122 candidate offspring $(59 \%)$ were assigned to 52 of $125 \mathrm{CPs}$ in six populations. Estimates of mean litter size were 1.5 young (range $1-3)$. The $50 \mathrm{CO}(41 \%)$ not assigned to a reproducing female in the study site were considered immigrants. Parentage assignment also provided evidence of dispersal between two of our sites. Overall, CMR and CERVUS agreed in $77 \%$ of cases. Considering only the 55 juveniles determined as locally born by CMR, $50(91 \%)$ were also assigned as local offspring with CERVUS. The main discrepancy between the two methods was that 22 subadult squirrels classified immigrants by CMR, were assigned by CERVUS to females which had reproduced in our sites. It is concluded that although in our study system agreement between CMR and CERVUS in determining local off-
\end{abstract}

E. Di Pierro - A. Martinoli - D. Preatoni - G. Tosi ·

L. A. Wauters $(\bowtie)$

Department Environment, Health, Safety, University of Insubria, Via Dunant 3, 21100 Varese (VA), Italy

E-mail: 1.wauters@uninsubria.it

S. Bertolino

DIVAPRA, Entomology and Zoology, University of Turin,

Via L. da Vinci 44, 10095 Grugliasco (TO), Italy

Present address: E. Di Pierro

Environment and Natural Resources Area,

FEM-IASMA Research Centre,

Via E. Mach 138010 San Michele all'Adige,

Trento (TN), Italy spring was high, using genetic parentage assignment helped to correctly classify some subadults, considered immigrants by CMR, as locally born. Hence, in largescale demographic studies, combining CMR with parentage assignment will allow more precise estimates of reproduction and dispersal.

Keywords Body mass - DNA microsatellite analysis Immigrants $\cdot$ Parental assignment $\cdot$ Sciurus vulgaris

\section{Introduction}

In traditional studies on population dynamics of birds and mammals, local birth and/or recruitment rates, survival rates, and immigration rates (dispersal rates) are inferred from combined nest-box-intensive (color) ringing studies (e.g., Greenwood 1980; Matthysen et al. 1995; Lens et al. 2002), or capture-mark-recapture data (CMR, Stenseth and Lidicker 1992; Berteaux and Boutin 2000; Boutin et al. 2006). Capture-mark-recapture analyses have been used in both open populations or in experimental, fenced situations, where dispersal can be controlled for (e.g., Diffendorfer et al. 1995; Byrom et al. 2000; Andreassen and Ims 2001). More recently, a growing number of detailed studies have used radiotracked juveniles of known origin to discover dispersal patterns and distances, and factors affecting settlement and survival by philopatric or dispersing juveniles (Larsen and Boutin 1994; Byrom and Krebs 1999; Haughland and Larsen 2004; Selonen et al. 2007). Both approaches have some drawbacks. Radio-tracking of juveniles is mainly successful for species with a high degree of philopatry and/or short dispersal distances, so that probability of losing radio-contact with animals moving over long distances is low. Capture-markrecapture studies assume that unmarked immigrants at first capture can be distinguished from unmarked locally born offspring. However, this assumption is met only when juveniles from resident litters can be marked in or near the nest (e.g., Larsen and Boutin 1994; Wauters and 
Dhondt 1995; Berteaux and Boutin 2000; Millar and McAdam 2001), which in many studies on population dynamics of small mammals is not the case (e.g., Dooley and Bowers 1998; Julliard et al. 1999).

These problems can be resolved by analyzing microsatellite DNA sequences of sufficient highly variable loci, using software to identify parentage (CERVUS, Marshall et al. 1998), in other words, to reveal kinship, and estimate the probability for parent-offspring bonds from genetic markers (Slate et al. 2000; Kalinowski et al. 2007). Recently, it has been shown that success in parental assignment can be increased by correcting for genotyping error (Kalinowski et al. 2007), and by combining genetic data with behavioral (reproductive activity) and spatial data from the sampled populations (e.g., Shurtliff et al. 2005; Hadfield et al. 2006; Lane et al. 2008).

The aim of this paper was to compare estimates of reproductive rate based on traditional standardized CMR of reproducing (pregnant and/or lactating) females and juvenile individuals, with genetic assignment of mother-offspring bonds in an arboreal mammal, the Eurasian red squirrel (Sciurus vulgaris). In our study system, juvenile squirrels were not marked inside nests or trapped under nest-trees, but during periodic CMR sessions. Hence, not all juveniles were marked before reaching age at which dispersal starts (4-5 months old, Wauters and Dhondt 1993, 1995) and might have been classified incorrectly as immigrants. To estimate whether and to what extend classification of individuals as locally born offspring, or as immigrants, using CMR (e.g., Wauters et al. 2004, 2008) was correct, we compared their assignment by CMR with genetic offspring assignment using CERVUS.

\section{Materials and methods}

\section{Study areas and populations}

We studied six populations of Eurasian red squirrels in montane and subalpine conifer forests in the Italian Alps and obtained data from CMR and microsatellites during 2001-2003. All study sites were mature, secondary montane and subalpine mixed conifer forests of the Italian Alps, with elevations ranging from 1100 to $2100 \mathrm{~m}$ a.s.l. (the upper tree-line), and distributed over two geographic regions. Two sites in the Cogne (COG) and Rhemes (RHE) Valleys of the Gran Paradiso National Park (western Alps), and four sites in the Valtellina Valley, Central Alps: Cedrasco (CED), OGA, Valfurva (VAL), and Bormio (BOR). Details of the study populations, squirrel density, landscape, tree species composition and specific location and distances between study sites have been reported previously (e.g., Trizio et al. 2005; Wauters et al. 2008). The social system of this species is based on, predominantly intra-sexual, hierarchical relationships formed through agonistic encounters between both resident and immigrant individuals, and intrasexual territoriality among adult, reproducing females (Wauters and Dhondt 1989, 1992; Wauters et al. 1990). In our alpine populations, mating occurred from January to May and litters (1 or 2/year) were born from March to July; at higher elevations females often had single litter with parturition in May.

Immigrants are usually subadult individuals that disperse from their natal home range after weaning and attempt to settle (recruit) in a new area (Wauters and Dhondt 1993; Wauters et al. 1993). Few juveniles settle close to their birthplace and strict philopatry, offspring settling in or near their mother's home range, is rare (Wauters et al. 1993, 1994). In previous studies, locally born juveniles were recognized as pre-weaned young marked in the nest of radio-collared, lactating females, as pre-weaned young trapped around the nest tree (Wauters and Dhondt 1995), and as (weaned) juveniles marked in standard trapping sessions: animals weighing less than $250 \mathrm{~g}$ and with external genitalia typical for juveniles (females: ano-genital distance $<4 \mathrm{~mm}$, small pink vulva and unvisible nipples; males: no or very small unstained scrotum, abdominal testes, and ano-genital distance $>8 \mathrm{~mm}$; Wauters and Dhondt 1995). Among the latter group, there is a certain degree of uncertainty, since onset of dispersal is variable (between 4 and 10 months old, Wauters unpubl. data) and dispersal behavior may vary among habitats (e.g., Lurz et al. 1997; Wauters et al. 2005). Therefore, to determine possible offspring-candidate parent $(\mathrm{O}-\mathrm{CP}$ pairs $)$ relationships for maternal assignment using the CERVUS 3.0 software (Kalinowski et al. 2007), we included all immature squirrels (juveniles and subadults) as candidate offspring (see below).

\section{Trapping and sampling techniques}

Squirrels were live-trapped in three separate sessions per year, starting in April, July, and October. Capture sessions were deliberately spaced out to include spring, summer, and autumn, as to maximize the probability of trapping recently weaned animals and determine the reproductive status of females (Wauters et al. 2007, 2008). A trapping session involved the use of 20-30 ground-placed Tomahawk traps (models 201 and 202, Tomahawk Live Trap Co., WI, USA). Traps were placed on a grid, with distances of $100-150 \mathrm{~m}$ between traps and average trap density of $0.6-0.7$ traps $\mathrm{ha}^{-1}$. Traps were pre-baited with sunflower seeds and hazelnuts four to six times over a 30-day period, and then baited and set for 8-12 days, until no new, unmarked squirrels were trapped for at least two consecutive days. This was done to ensure trapping and sampling of most squirrels that immigrated to the study areas (e.g., Wauters and Dhondt 1993; Wauters et al. 2008). Traps were partly covered by dark plastic to give shelter from rain or cold, and checked two to three times per day. Each trapped squirrel was flushed into a light cotton handling bag with a zipper (Wauters et al. 2007), or a 
wire-mesh 'handling cone' to minimize stress during handling, and individually marked using numbered metal ear-tags (type $1003 \mathrm{~S}, 10$ by $2 \mathrm{~mm}$, National Band and Tag Co, Newport, KY, USA). It was weighed to the nearest $5 \mathrm{~g}$ using a Pesola spring-balance (Pesola AG, Baar, Switzerland). Sex, age, and reproductive condition were recorded following Wauters and Dhondt (1995). At each (re)capture, reproductive status of females was scored as anestrous (vulva small, not perforated), estrous or pregnant (vulva pink swollen or enlarged, perforated or with a clearly visible suture), or lactating (nipples pink and swollen, milk excretion can be stimulated, fur removed around nipples; by the end of lactation and 1-2 week post-lactation nipples are still enlarged and often pigmented) (Wauters and Dhondt 1989, 1995).

\section{Molecular analyses and maternity assignment}

DNA was extracted from ear tissue (3-mm biopsy punch) using a standard phenol-chloroform protocol (for details see Trizio et al. 2005). Individuals were genotyped at ten microsatellite loci (SCV4 (GT)23, SCV9 (ACAG)3(AC)14, SCV12 (TG)15(CACG)2, SCV13 (GA)15, SCV19 (TG) 11, GeneBank accession numbers AF309452, AF309455, AF309457, AF309458, AF309463, respectively, Hale et al. 2001; and Rs $\mu 1$ (GGAT)13, Rs $\mu 3$ (GA)9(GACA)9, Rs $\mu 4$ (ATCC)12, Rs $\mu 5$ (GT)10, Rs $\mu 6$ (GTT)10, GeneBank accession numbers from AF285149 to AF285153, Todd 2000). Polymerase chain reaction (PCR) amplifications were carried out in $10-\mu \mathrm{l}$ reaction volumes containing $1 \times$ buffer $\left(10 \mathrm{mM}\right.$ Tris- $\mathrm{HCl}, \mathrm{pH} 8.8,1.5 \mathrm{mM} \mathrm{MgCl}_{2}$, $50 \mathrm{mM} \mathrm{KCl}$ and $0.1 \%$ Triton X-100), $200 \mu \mathrm{M}$ dNTPs, $0.33-0.4 \mathrm{mM}$ of each primer, $2.5-3 \mathrm{mM} \mathrm{MgCl}_{2}, 0.6 \mathrm{U}$ Taq polymerase (FINNZYMES) and $100-300 \mathrm{ng}$ genomic DNA. PCR amplifications were performed following protocols in Todd (2000) and Hale et al. (2001). PCR products were analyzed by an ALFexpress II DNA analyzer (Amersham Pharmacia Biotech) and ALLELELINKS version 1.02 software (Amersham Pharmacia Biotech). Internal and external standards were used and reference samples with known genotype for each locus were included in each run to ensure reliable scoring of genotypes across different gels.

We only tried to determine mothers in offspringcandidate parent $(\mathrm{O}-\mathrm{CP}$ pairs) relationships using CERVUS 3.0 (Kalinowski et al. 2007). Eurasian red squirrels in alpine populations may have one or two litters per year. Therefore, $\mathrm{CP}$-mothers were all adult females trapped in a given year that were found pregnant and/or lactating in at least one of the three trapping sessions (Wauters and Dhondt 1995; Wauters et al. 2007). Hence, for a juvenile caught in trapping session $t$ (summer or autumn session), potential mothers were adult females scored as pregnant in session $t-1$, lactating or post-lactation in session $t$, or post-lactation in session $t+1$. The percentage of pregnant/lactating females that were genotyped (could be analyzed as $\mathrm{CP}$-mothers) varied from $72 \%$ in 2001 (13 out of 18 ), to $95 \%$ in 2002 (56 out of 59) and $100 \%$ (56) in 2003 (Table 1). Candidate offspring were all squirrels first caught as juveniles (locally-born offspring, 6 weeks4 months old, body mass below $250 \mathrm{~g}$, Wauters et al. 1993, 2004), and squirrels first caught as subadults or yearlings (>250 g, 5-12 months old; males with abdominal testes and small scrotum; nulliparous females with small vulva and nipples still invisible, Wauters and Dhondt 1993). The latter were of unknown origin: they might be offspring of parous females resident in the study area, or have been born elsewhere and immigrated.

Maternity was assigned at 95 and $80 \%$ confidence using CERVUS 3.0 (Kalinowski et al. 2007). The CERVUS 3.0 software estimates the relative likelihood of parentage and a level of confidence for parentage assignment, taking into account genotyping errors and the possibility that the true parent was not sampled. For the simulation step of CERVUS to determine confidence levels we used: 100000 cycles ('offspring'), between 3 and 17 candidate mothers, $90 \%$ of the population sampled, and $95 \%$ of all loci genotyped with a $1 \%$ level of genotyping error. When a species is highly philopatric, relatedness among candidate parents must be considered in CERVUS simulations (e.g., Lane et al. 2008 for Tamiasciurus hudsonicus). However, Eurasian red squirrels, of either sex, tend to disperse from the natal home range (Wauters and Dhondt 1993; Wauters et al. 1994b; our unpubl. data): hence it is unlikely that candidate mothers are (close) relatives. Therefore, we assumed there were no relatives among candidate mothers. Separate analyses were conducted for each of the years 2001, 2002, and 2003, and in each of the study sites (see also Lane et al. 2007, 2008). However, CP-mothers of VAL and BOR were tested against candidate offspring of both sites since the shortest distance between these two sites was only $1.1 \mathrm{~km}$, a distance easily crossed by dispersing squirrels (our unpublished data, Wauters et al. 2005). None of the mothers assigned by CERVUS had more than one mismatch with the genotype of its offspring.

To make sure that relatedness among some candidate mothers would not change our results, we explored possible effects of relatedness simulating relatives among the pool of candidate parents on a subset of our data (83 CO for 70 CP from BOR\&VAL 2002, OGA 2002 and 2003, RHE 2002 and 2003, Cogne 2002) with the following parameters: $15 \%$ of candidate mothers related at 0.125 . There were no differences in offspring assignment with or without relatedness and we only show results for simulations with no relatedness among candidate mothers.

Finally, to investigate the reliability of maternity assignment at $80 \%$ to true mothers, we simulated pairs of offspring with impossible $\mathrm{CP}-$ mothers ('false' $\mathrm{CP}$ mothers), using subadult females or adult females that did not produce a litter in a given year. Also here 
Table 1 Number of red squirrels trapped and used in CERVUS analysis by study site and year

\begin{tabular}{|c|c|c|c|c|c|c|c|}
\hline & OGA & CED & $\mathrm{VAL}^{\mathrm{a}}$ & $\mathrm{BOR}^{\mathrm{a}}$ & RHE & $\mathrm{COG}$ & Total \\
\hline Mean number of alleles & 5.0 & 4.7 & 5.4 & 4.8 & 4.8 & 4.6 & \\
\hline$H_{\mathrm{E}}$ & 0.598 & 0.548 & 0.615 & 0.564 & 0.562 & 0.493 & \\
\hline$H_{\mathrm{O}}$ & 0.588 & 0.532 & 0.539 & 0.589 & 0.477 & 0.490 & \\
\hline \multicolumn{8}{|l|}{2001} \\
\hline Candidate offspring ${ }^{\mathrm{b}}$ & $4(1)$ & & & & $7(6)$ & $6(6)$ & $17(13)$ \\
\hline Candidate mothers & $3(2 \mathrm{NG})$ & & & & $5(2 \mathrm{NG})$ & $5(1 \mathrm{NG})$ & $13(5 \mathrm{NG})$ \\
\hline Offspring assigned ${ }^{\mathrm{C}}$ & 1 & & & & $4(3)$ & 6 & 11 \\
\hline Immigrants & 3 & & & & 3 & 0 & 5 \\
\hline Successful mothers & $1(33 \%)$ & & & & $4(80 \%)$ & $3(60 \%)$ & \\
\hline \multicolumn{8}{|l|}{2002} \\
\hline Candidate offspring ${ }^{\mathrm{b}}$ & $12(5)$ & $4(1)$ & $20(3)$ & $13(8)$ & $17(7)$ & $8(6)$ & $74(30)$ \\
\hline Candidate mothers ${ }^{\mathrm{a}}$ & 8 & 6 & $17(25)(3 \mathrm{NG})$ & $8(25)$ & 8 & 9 & $56(3 \mathrm{NG})$ \\
\hline Offspring assigned ${ }^{\mathrm{c}}$ & $7(3)$ & 1 & $12(1)$ & $8(3)$ & $9(3)$ & 7 & 44 \\
\hline Immigrants ${ }^{\mathrm{d}}$ & 5 & 3 & 5 (3 BOR) & 5 (3 VAL) & 8 & 1 & 27 \\
\hline \multirow{2}{*}{\multicolumn{8}{|c|}{2003}} \\
\hline & & & & & & & \\
\hline Candidate offspring ${ }^{\mathrm{b}}$ & $5(1)$ & $5(2)$ & $6(2)$ & $4(3)$ & $8(2)$ & $6(3)$ & $34(12)$ \\
\hline Candidate mothers $^{\mathrm{a}}$ & 9 & 6 & $14(17)$ & $3(17)$ & 11 & 13 & 56 \\
\hline Offspring assigned ${ }^{c}$ & 1 & 2 & $1(1)$ & 3 & $5(1)$ & 5 & 17 \\
\hline Immigrants & 4 & 3 & 5 (1 BOR $)$ & 1 & 3 & 1 & 17 \\
\hline Successful mothers & $1(11 \%)$ & $2(33 \%)$ & $1(7 \%)$ & $2(67 \%)$ & $4(36 \%)$ & $5(38 \%)$ & \\
\hline
\end{tabular}

Mean number of alleles per locus, expected $\left(H_{\mathrm{E}}\right)$ and observed $\left(H_{\mathrm{O}}\right)$ heterozygosities from Trizio et al. (2005)

$N G$ between brackets number of potential mothers (pregnant or lactating females) not genotyped, thus not used in CERVUS

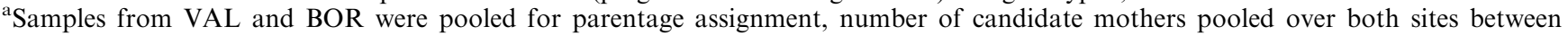
brackets

${ }^{\mathrm{b}}$ Candidate offspring identified as locally born juveniles with CMR between brackets

${ }^{c}$ Number offspring assigned with $95 \%$ confidence between brackets)

${ }^{\mathrm{d}}$ Immigrants that were assigned to mothers from VAL and BOR. Successful mothers are mothers to which at least one offspring was assigned ( $\%$ successful on candidate mothers between brackets). Confidence offspring assignment set at $80 \%$

CERVUS analyses were conducted for each year separately (except for CED and OGA, years combined) and in each of the study sites (except BOR and VAL, sites combined). For the ten datasets that were analyzed, between six and 19 offspring and between five and ten 'false $\mathrm{CP}-$ mothers were used, for a total of 92 candidate offspring and 83 'false' $\mathrm{CP}$-mothers. These simulations tested 787 possible offspring-mother pairs. All other CERVUS input parameters as above.

\section{Results}

Overall, 125 candidate offspring (CO) and 125 candidate mothers were analyzed. Nine pregnant or lactating females, hence potential mothers, were trapped and marked but not genotyped, and thus not included in CERVUS analysis (Table 1). Among 125 candidate offspring, there were three cases in VAL of not assigned juveniles (body mass $<190 \mathrm{~g}$ ) in 2002, when also three potential mothers were not genotyped (Table 1). These three juveniles were excluded from further analysis.

Over all sites and years, 72 of 122 CO $(59 \%)$ were assigned to 52 litters of reproducing females (or mothers within year), against $50(41 \%)$ that could not be assigned to a reproducing females inside the same study site (Table 1). The latter were considered immigrants. In 61 of the 72 cases of offspring - assigned mum $(85 \%)$ there was no allelic mismatch, while in the remaining 11 cases there was one allelic mismatch. In VAL, four out of ten $(40 \%)$ immigrants were assigned to candidate mothers from BOR, while in BOR three out of six $(50 \%)$ immigrants were assigned to mothers from VAL. This is the first evidence of dispersal between both sites with successive settlement of subadult squirrels. The three subadults in BOR were trapped between June and $\mathrm{Au}-$ gust 2002 and weighed between 230 and $265 \mathrm{~g}$, which suggested that potential mothers were lactating in AprilJuly. The mothers in VAL assigned to these three animals where trapped early September with enlarged but dry nipples, indicating that they weaned a litter some months earlier. Likewise, three subadults (255-280 g), trapped in VAL between 18 and 20 July, were assigned to mothers from BOR lactating late May - early June. Taking into account also these immigrants from known mothers, mean litter size ( \pm SD) of offspring assigned with CERVUS was $1.50 \pm 0.74$ young/litter (range $1-3$, $n=52$ ), and there was no difference in mean litter size between study sites (ANOVA $F_{5,46}=0.55, p=0.74$ ). In 2002, two females, which had a spring and a summer litter weaned four and five offspring, respectively.

\section{CERVUS-CMR comparisons}

Using body mass and external genitalia from CMR we defined 55 juvenile squirrels as locally born offspring. 
Five of these could not be assigned to reproducing females in the study sites, while $50(91 \%)$ were assigned as local offspring with CERVUS. However, CERVUS assigned another 22 squirrels to local candidate mothers, that, using body mass and external genitalia from CMR had been classified as subadults. Among the 66 squirrels considered subadult immigrants with CMR, $44(67 \%)$ could not be assigned to reproducing females in the study sites and thus were also classified as immigrants using CERVUS. Thus, overall CMR and CERVUS resulted in the same classification of locally born offspring or immigrated subadults in 94 out of 122 cases $(77 \%)$, but discrepancies between the two methods differed among study sites (Table 2; log-linear model factor 'classification' Wald $\chi^{2}=51.8$, $\mathrm{df}=1, p<0.0001$; classification by site interaction factor Wald $\chi^{2}=13.5$, $\mathrm{df}=5, p=0.019)$. The largest discrepancy between the two methods in assigning squirrels as offspring from females reproducing in our study sites was that CERVUS assigned 22 subadults to local females $(30 \%$ of 72 offspring), that, based on their age and mass at first capture, had been classified as immigrants by CMR. In site VAL, 9 subadults were assigned to local mothers by CERVUS, but considered immigrants using CMR. However, all these were caught in the first year this site was monitored, when no trapping was carried out in April-May: thus juveniles from early litters, born in March, were at least 4 months old in the second half of July (first trapping session) and 6 months old in the September trapping session. At these ages, external genitalia start to develop and body mass is likely to be higher than $250 \mathrm{~g}$ (see also Wauters et al. 1993, 2007). Without the VAL data, correct assignment (correspondence between the two methods) increased to 81 out of 99 cases $(81 \%)$.

\section{The 'false' mother simulations}

To explore the reliability of the CERVUS parentage assignment at $80 \%$ in our dataset, we performed simulations of candidate offspring against 'false' candidate mothers ('false'-CPs). In only eight out of 787 possible offspring-'false' mother pairs $(1 \%)$, offspring were assigned to a 'false'-CP. Hence incorrect assignment with $80 \%$ confidence level was very unlikely in our red squirrel dataset and there were no cases of incorrect assignment at $95 \%$ confidence level. Thus, in the original offspring-CP analysis, reproducing females assigned with $80 \%$ and with $95 \%$ confidence were considered true mothers.

\section{Discussion}

How reliable was parentage assignment?

The type of samples obtained from natural populations has great implications for the reconstruction of parentage in studies using a combination of polymorphic molecular markers (DNA microsatellites), parentage analysis methods based on maximum likelihood estimators, and exclusion of individuals as potential parents (Jones and Ardren 2003; Telfer et al. 2003; Koch et al. 2008). Although the joint combination of these methods greatly increases the correct parentage assignment, the risk of two types of errors remains: false parentage assignment and the nondetection of true parents, in our case mothers (e.g., Oddou-Muratorio et al. 2003; Shurtliff et al. 2005). In the natural populations of red squirrels used in this study, the sampling design was characterized by (1) all, or in a few cases the majority, of the candidate parents (mothers) were sampled; (2) neither parent of offspring was known a priori, but a number of candidate mothers was restricted based on reproductive activity revealed by trapping; (3) no large groups of full- or half-sibs were sampled. In this case, categorical allocation of mothers using CERVUS is indicated (Jones and Ardren 2003). However, erroneous assignment or nondetection of candidate parents (CPs) will be affected by: (1) the number of microsatellites loci used and their polymorphic information content (e.g., Lemos et al. 2006); (2) absence of demographic data and/or ignorance regarding the completeness of parental sampling (e.g., Koch et al. 2008); and (3) rate of scoring error in genotype assessment (e.g., Oddou-Muratorio et al. 2003). To reduce these types of errors, we combined detailed demographic data with a maximum

Table 2 Comparison of the number of red squirrel candidate offspring assigned as locally born offspring or as immigrant by CMR and its assignment by CERVUS in six study sites

\begin{tabular}{|c|c|c|c|c|}
\hline $\begin{array}{l}\text { Study site and \% } \\
\text { correctly assigned }\end{array}$ & $\begin{array}{l}\text { Local offspring } \\
\text { CMR and CERVUS }\end{array}$ & $\begin{array}{l}\text { Local offspring CMR } \\
\text { not } \\
\text { CERVUS }\end{array}$ & $\begin{array}{l}\text { Immigrant CMR } \\
\text { not CERVUS }\end{array}$ & $\begin{array}{l}\text { Immigrant CMR } \\
\text { and CERVUS }\end{array}$ \\
\hline OGA $(76 \%)$ & 6 & 2 & 3 & 10 \\
\hline CED $(100 \%)$ & 3 & 0 & 0 & 6 \\
\hline VAL $(57 \%)$ & 4 & 1 & 9 & 9 \\
\hline BOR $(76 \%)$ & 9 & 2 & 2 & 4 \\
\hline RHE $(81 \%)$ & 13 & 1 & 5 & 13 \\
\hline $\operatorname{COG}(85 \%)$ & 15 & 0 & 3 & 2 \\
\hline Total $(77 \%)$ & 50 & 6 & 22 & 44 \\
\hline
\end{tabular}

$\%$ Correctly assigned is the \% of candidate offspring classified in the same group (local offspring or immigrant) by both methods (CMR and CERVUS) 
likelihood estimator that accounted for genotyping error (CERVUS vs 3.0, Kalinowski et al. 2007) and with allelic mismatching between offspring and CPs.

First, in this study we used ten microsatellite loci, with allele numbers ranging from four to ten per locus (mean 5.8, Trizio et al. 2005). Moreover, red squirrels from all six populations showed high levels of heterozygosity at the ten loci and gene diversity $H_{\mathrm{E}}$ ranged from 0.49 in COG to 0.61 in VAL (Trizio et al. 2005). The number of microsatellite loci used to assign parents in this study was within the range of loci used in other vertebrate studies obtaining successful parentage assignment using CERVUS (four microsatellite markers in the canyon mouse, Shurtliff et al. 2005; eight markers, Lemos et al. 2006; 12-17 markers for a variety of mammals, Aars et al. 2006; Castagnasso et al. 2007; Lane et al. 2008; up to 22 markers in badgers, Dugdale et al. 2007).

Second, intensive CMR data allowed us to achieve a high level of completeness of parental sampling. In fact, exact determination of potential mothers from morphological parameters of reproductive activity (see Materials and methods) and nearly complete genotyping of candidate mothers in 2002 and 2003 (95\% of 59 CPs and $100 \%$ of $56 \mathrm{CPs}$, respectively) allowed us to reduce this source of error (see also Oddou-Muratorio et al 2003; Aars et al. 2006; Koch et al. 2008). This was further supported by our results: the only three cases, among 125 candidate offspring, of locally born offspring with nondetection of the mother were in VAL in 2002, where three potential mothers were not genotyped. Only in the first year, 2001, genotyping of potential mothers was less complete $(72 \%)$, and only in this year nondetection of mothers using CERVUS occurred in OGA and RHE. We had no cases of CERVUS not detecting mothers among the CPs in sites CED and COG. Hence we had few cases of nondetection of candidate mothers when offspring were without doubt locally born young ( 5 on $125,4 \%$ ), probably all cases where the real mother was not genotyped. Finally, as an input parameter for the simulation step of CERVUS, we considered that $90 \%$ of the population was sampled, to account for incomplete sampling of potential mothers. This was further combined with checking for allelic mismatching between offspring and CPs. In only $15 \%$ of 72 cases of assigned mothers there was one allelic mismatch and we had no cases of an assigned parent with more than one allelic mismatch. Using these CERVUS input/output parameters should have reduced erroneous assignment of CPs as true mother (Kalinowski et al. 2007).

Third, the rate of scoring error in genotype assessment was accounted for in the CERVUS version 3.0 we used (Kalinowski et al. 2007).

One problem that remains, however, is the confidence level of parentage-assignment. In several studies only parents assigned with a $95 \%$ probability were considered (e.g., Aars et al. 2006; Dugdale et al. 2007; Lane et al. 2008). In our study system it was impossible to exclude the candidate mothers (CPs) assigned with a $80 \%$ confidence (see also Telfer et al. 2003). Our choice of retaining these CPs was supported by the simulations of candidate offspring - 'false', non-reproducing, CPs, that demonstrated that only in $1 \%$ of cases $(n=787$ offspring- $\mathrm{CP}$ combinations) a false $\mathrm{CP}$ was assigned as the mother with an $80 \%$ confidence. Hence, we considered the reproducing females assigned with an $80 \%$ confidence as true mothers of the immature squirrels included in the CERVUS analyses.

\section{Agreement between CERVUS offspring assignment} and $\mathrm{CMR}$

There was a good agreement between CERVUS offspring assignment to local mothers and CMR definition of locally born juveniles $(91 \%)$, suggesting that estimates of reproductive rate used in previous studies on the dynamics of alpine squirrel populations are robust (Wauters et al. 2008). Only in five cases a juvenile classified as locally born by CMR had no mum assigned by CERVUS, two in a situation when not all potential mothers were genotyped. In the other three cases where no mum was assigned, we believe that the true mother was not trapped, either because it lived just outside the trapping grid, or it was present only for a few months. Litter size estimated with CERVUS ranged from one to three weaned young, similar to CMR estimates from intensive trapping in populations in Belgium (Wauters and Dhondt 1995; Wauters and Lens 1995). However, mean litter size with CERVUS in the six alpine populations (1.5 weaned young) was smaller than a multiyear average in the Belgian populations (ca. 2.0 weaned young, Wauters and Lens 1995). Since offspring mortality and average litter size at weaning varied with pineseed food abundance (Wauters and Lens 1995), lower estimates in our alpine populations, for the period 20012003, may be caused by reduced food availability in some years and sites. However, it may also have been caused by lower trapping effort and success, in particular for juveniles, than in the Belgian populations.

The main discrepancy between the two methods in our study sites was that 22 subadult squirrels, weighing more than $250 \mathrm{~g}$ and thus classified immigrants by CMR, were assigned by CERVUS to females which had reproduced in our sites. Thus, with three trapping sessions per year, 22 of 72 local offspring $(30 \%)$, were trapped for the first time when more than 4-5 months old. Among these 22 local offspring, ten were sampled in the first year of the study when juveniles from spring litters could not have been caught when less than 4 months old, since the first trapping session was held in July. Hence, based on body mass measured with CMR they would have been classified as immigrants. Previous studies of red squirrel demography, which used CMR and body mass at first capture to distinguish locally born juveniles from dispersers and to estimate reproductive and immigration rates, had more frequent trapping sessions that continued throughout the year (Wauters 
and Dhondt 1993, 1995; Kenward et al. 1998; Gurnell et al. 2004; Wauters et al. 2004). Moreover, in some studies, local offspring were marked in the nest or by extra trapping around nest trees (Wauters and Dhondt 1995; Wauters et al. 2004; Mari et al. 2008), which allowed to determine offspring-mother bonds without checking genotypes (see also Berteaux and Boutin 2000; Haughland and Larsen 2004; Boutin et al. 2006; Lane et al. 2008). In our study project, the intensity of fieldwork was limited by the period that the study sites were accessible (from April-May to October) and also by logistic constraints. Since the main objective was to explore producer-consumer dynamics over a range of environmental conditions, we opted for standardized CMR methods in different forest habitats with no special effort to trap young early in life, since this would have created methodological bias among sites.

Can dispersal rates be inferred from the non-assignment of immature animals to one of the candidate parents?

Whereas $59 \%$ of our 122 candidate offspring were assigned to females reproducing within one of our study sites, the remaining $41 \%$ did not have a candidate mum and were considered immigrants. If we defined immigrants as in earlier studies using CMR and body mass, our estimate of proportion immigrants increased to $54 \%$ of the candidate offspring. Hence, CMR slightly overestimated immigration rates (of immature squirrels) in these alpine squirrel populations, where trapping was carried out less frequent than in earlier studies in Belgium (Wauters et al. 2004, 2008). Nevertheless, 75\% of immature squirrels not assigned by CERVUS to reproducing females, and thus classified as immigrants, weighed more than $260 \mathrm{~g}$ at first capture, which corresponded well with the $>250$ g cut-off point to classify subadults as dispersers.

Rates of dispersal, inferred with either method, were high, supporting earlier findings based on heterozygosities, allelic richness, and population substructuring, which showed that squirrels from sites CED, VAL, and BOR represent a single population with constant gene flow between these sites (Trizio et al. 2005). We also had direct evidence of natal dispersal between sites BOR and VAL, since CERVUS revealed mothers resident in BOR for $40 \%$ of immature immigrants captured in VAL, and mothers resident in VAL for $50 \%$ of immature immigrants captured in BOR. Using the distance between traps where pairs of dispersed offspring-mothers were trapped (e.g., the distance between the location of the trap in BOR where a mum was trapped and the location of the trap in VAL where its offspring was caught) we obtained dispersal distances of $1.7-2.7 \mathrm{~km}$ in contiguous forest. Apart from true natal dispersal, some of these squirrels might have also been involved in dispersal movements linked with temporary food-shortage in monospecific forest stands (see Wauters et al. 2005). In fact, in 2002 there was seed-crop failure of Arolla pine, the dominant tree species in BOR (77\% of tree-cover, elevations 1900-2150 m a.s.l., Di Pierro et al. 2008; Wauters et al. 2008), so many squirrels might have been forced to emigrate towards the lower-elevation Norway spruce forests in and near the VAL study site (1550-1800 m a.s.l.).

In conclusion, estimates of vital rates, in particular reproductive rate and dispersal (immigration) rate, in demographic studies of small and medium-sized mammals will be affected by trapping intensity and/or frequency. The major risk is that locally weaned offspring is not trapped, and thus identified, before natal dispersal occurs. Hence, some of them will be trapped for the first time at a later age (as subadults) and therefore erroneously defined as immigrants using 'traditional' CMR classification rules. We showed that performing parentage assignment based on microsatellite markers using the CERVUS software reduced this risk. Where in our study system agreement between CMR and CERVUS in determining local offspring was high, using genetic parentage assignment helped to correctly classify some subadults, considered immigrants by CMR, as locally born offspring. Hence in large-scale demographic studies combining CMR data with parentage assignment tests of immature individuals could improve estimates of reproductive and dispersal rates (e.g., Aars et al. 2006), vital parameters to explore the relative effects of exogenous and endogenous factors on population change and regulation (Turchin 1999; Wauters et al. 2004).

Acknowledgments We are grateful to Ambrogio Molinari, Massimiliano Zaninetti, and Giuseppe Airoldi for their help with the fieldwork. This study is part of the ASPER (Alpine Squirrel Population Ecology Research) project, funded by the province of Sondrio (Servizio Agricoltura, Caccia e Pesca, Settore Risorse Ambientali), the Gran Paradiso National Park, the Stelvio National Park and the Parco Regionale delle Orobie Valtellinesi to Istituto Oikos NGO, Milan. Additional financial support was given by MIUR (Ministero dell'Istruzione, dell'Università della Ricerca, project COFIN 2003, number 2003053710-006) to Insubria University of Varese. Trapping and handling squirrels complied with the current laws on animal research in Italy and were carried out under permission of the Region of Lombardy. This is paper \#17 of the ASPER project.

\section{References}

Aars J, Dallas JF, Piertney SB, Marshall F, Gow JL, Telfer S, Lambin X (2006) Widespread gene flow and high genetic variability in populations of water voles Arvicola terrestris in patchy habitats. Mol Ecol 15:1455-1466

Andreassen HP, Ims RA (2001) Dispersal in patchy vole populations: role of patch configuration, density dependence, and demography. Ecology 82:2911-2926

Berteaux D, Boutin S (2000) Breeding dispersal in female North American red squirrels. Ecology 81:1311-1326

Boutin S, Wauters LA, McAdam AG, Humphries MM, Tosi G, Dhondt AA (2006) Anticipatory reproduction and population growth in seed predators. Science 314:1928-1930

Byrom AE, Krebs CJ (1999) Natal dispersal of juvenile arctic ground squirrels in the boreal forest. Can J Zool 77:1058-1059

Byrom AE, Karels TJ, Krebs CJ, Boonstra R (2000) Experimental manipulation of predation and food supply of arctic ground squirrels in the boreal forest. Can J Zool 78:1309-1319 
Di Pierro E, Molinari A, Tosi G, Wauters LA (2008) Exclusive core areas and intrasexual territoriality in Eurasian red squirrels (Sciurus vulgaris) revealed by incremental cluster polygon analysis. Ecol Res 23:529-542

Diffendorfer JE, Gaines ME, Holt RD (1995) Habitat fragmentation and movements of three small mammals (Sigmodon, Microtus and Peromyscus). Ecology 76:827-839

Dooley JR Jr, Bowers MA (1998) Demographic responses to habitat fragmentation: experimental tests at the landscape and patch scale. Ecology 79:969-980

Dugdale HL, MacDonald DW, Pope LC, Burke T (2007) Polygynandry, extra-group paternity and multiple paternity in litters in European badger (Meles meles) social groups. Mol Ecol 16:5294-5306

Greenwood PJ (1980) Mating systems, philopatry, and dispersal in birds and mammals. Anim Behav 28:1140-1162

Hadfield JD, Richardson DS, Burke T (2006) Towards unbiased parentage assignment: combining genetic. behavioural and spatial data in a Bayesian framework. Mol Ecol 15:3715-3730

Hale ML, Bevan R, Wolff K (2001) New polymorphic microsatellite markers for the red squirrel (Sciurus vulgaris) and their applicability to the grey squirrel ( $S$ carolinensis). Mol Ecol Notes 1:47-49

Haughland DL, Larsen KW (2004) Ecology of North American red squirrels across contrasting habitats: relating natal dispersal to habitat. J Mammal 85:225-236

Jones AG, Ardren WR (2003) Methods of parentage analysis in natural populations. Mol Ecol 12:2511-2523. doi:101046/ j1365-294X200301928x

Julliard R, Leirs H, Stenseth NC, Yoccoz NG, Prévot-Julliard AC, Verhagen R, Verheyen W (1999) Survival-variation within and between functional categories of the African multimammate rat. J Anim Ecol 68:550-561

Kalinowski ST, Taper ML, Marshall TC (2007) Revising how the computer program CERVUS accommodates genotyping error increases success in paternity assignment. Mol Ecol 16:10061099

Koch M, Hadfield JD, Sefc KM, Sturmnauer C (2008) Pedigree reconstruction in wild cichlid fish populations. Mol Ecol $17: 4500-4511$

Lane JE, Boutin S, Gunn MR, Slate J, Coltman DW (2008) Female multiple mating and paternity in free-ranging North American red squirrels. Anim Behav 75:1927-1937

Larsen KW, Boutin S (1994) Movements, survival, and settlement of red squirrel (Tamiasciurus hudsonicus) offspring. Ecology $75: 214-223$

Lemos A, Freitas AI, Fernandes AT, Goncalves R, Jesus J, Andrade C, Brehm A (2006) Microsatellite variability in natural populations of the blackspot seabream Pagellus bogaraveo (Brunnick, 1768): a database to access parentage assignment in aquaculture. Aquacult Res 37:1028-1033

Lens L, Van Dongen S, Norris K, Githiru M, Matthysen E (2002) Avian persistence in fragmented rainforest. Science 298:12361238

Lurz PWW, Garson PJ, Wauters LA (1997) Effects of temporal and spatial variation in habitat quality on red squirrel dispersal behaviour. Anim Behav 54:427-435

Mari V, Martini S, Romeo C, Molinari A, Martinoli A, Tosi G, Wauters LA (2008) Record litter size in the Eurasian red squirrel (Sciurus vulgaris). Hystrix It J Mamm (ns) 19:61-65

Marshall TC, Slate J, Kruuk LEB, Pemberton JM (1998) Statistical confidence for likelihood-based paternity inference in natural conditions. Mol Ecol 7:639-655

Matthysen E, Adriaensen F, Dhondt AA (1995) Dispersal distances of nuthatches Sitta europaea in a highly fragmented landscape. Oikos 72:375-381
Millar JS, McAdam AG (2001) Life on the edge: the demography of short-season populations of deer mice. Oikos 93:69-76

Oddou-Muratorio S, Houot ML, Demesure-Musch B, Austerlitz F (2003) Pollen flow in the wildservice tree, Sorbus torminalis (L) Crantz I. Evaluating the paternity analysis procedure in continuous populations. Mol Ecol 12:3427-3439

Selonen V, Hanski IK, Desrochers A (2007) Natal habitat-biased dispersal in the Siberian flying squirrel. Proc R Soc Lond B Biol Sci 274:2063-2068

Shurtliff QR, Pearse DE, Rogers DS (2005) Parentage analysis of the canyon mouse (Peromyscus crinitus): evidence for multiple paternity. J Mammal 86:531-540

Slate J, Marshall TC, Pemberton JM (2000) A retrospective assessment of the accuracy of the paternity inference program CERVUS. Mol Ecol 9:801-808

Stenseth NC, Lidicker WZ Jr (1992) Animal dispersal: small mammals as a model. Chapman and Hall, London

Telfer S, Piertney SB, Dallas JF, Stewart WA, Marshall F, Gow JL, Lambin X (2003) Parental assignment detects frequent and large-scale dispersal in water voles. Mol Ecol 12:1939-1949

Todd R (2000) Microsatellite loci in the Eurasian red squirrel, Sciurus vulgaris L. Mol Ecol 9:2165

Trizio I, Crestanello B, Galbusera P, Wauters LA, Tosi G, Matthysen E, Hauffe HC (2005) Geographical distance and physical barriers shape the genetic structure of Eurasian red squirrels (Sciurus vulgaris) in the Italian Alps. Mol Ecol 14:469-481

Turchin P (1999) Population regulation: a synthetic view. Oikos $84: 153-159$

Wauters LA, Dhondt AA (1989) Body weight, longevity and reproductive success in red squirrels (Sciurus vulgaris). J Anim Ecol 58:637-651

Wauters LA, Dhondt AA (1992) Spacing behaviour of the red squirrel, Sciurus vulgaris: variation between habitats and the sexes. Anim Behav 43:297-311

Wauters LA, Dhondt AA (1993) Immigration patterns and success in red squirrels. Behav Ecol Sociobiol 33:159-167

Wauters LA, Dhondt AA (1995) Lifetime reproductive success and its correlates in female Eurasian red squirrels. Oikos 72:402-410

Wauters LA, Lens L (1995) Effects of food abundance and density on red squirrel (Sciurus vulgaris) reproduction. Ecology 76:2460-2469

Wauters LA, Dhondt AA, De Vos R (1990) Factors affecting male mating success in red squirrels Sciurus vulgaris. Ethol Ecol Evol 2:195-204

Wauters LA, Bijnens L, Dhondt AA (1993) Body mass at weaning and juvenile recruitment in the red squirrel. J Anim Ecol 62:280-286

Wauters L, Matthysen E, Dhondt AA (1994) Survival and lifetime reproductive success in dispersing and resident red squirrels. Behav Ecol Sociobiol 34:197-201

Wauters LA, Matthysen E, Adriaensen F, Tosi G (2004) Withinsex density dependence and population dynamics of red squirrels Sciurus vulgaris. J Anim Ecol 73:11-25

Wauters LA, Bertolino S, Adamo M, Van Dongen S, Tosi G (2005) Food shortage disrupts social organization: the case of red squirrels in conifer forests. Evol Ecol 19:375-404

Wauters LA, Vermeulen M, Van Dongen S, Bertolino S, Molinari A, Tosi G, Matthysen E (2007) Effects of spatio-temporal variation in food supply on red squirrel Sciurus vulgaris body size and body mass and its consequences for some fitness components. Ecography 30:51-65

Wauters LA, Githiru M, Bertolino S, Molinari A, Tosi G, Lens L (2008) Demography of alpine red squirrel populations in relation to fluctuations in seed crop size. Ecography 31:104-114 